\title{
Article \\ COVID-19 and People Management: The View of Human Resource Managers
}

\author{
Sónia P. Gonçalves ${ }^{1, * \mathbb{C}}$, Joana Vieira dos Santos ${ }^{2}$, Isabel S. Silva ${ }^{3}$, Ana Veloso ${ }^{3} \mathbb{(}$, Catarina Brandão ${ }^{4}(\mathbb{D}$ \\ and Rita Moura ${ }^{5}$ (D) \\ 1 Centro de Administração e Políticas Públicas (CAPP), Instituto Superior de Ciências Sociais e Políticas, \\ Instituto de Saúde Ambiental (ISAMB), Universidade de Lisboa, 1300-663 Lisboa, Portugal \\ 2 Psychology Research Centre (CIP), Faculty of Human and Social Sciences, University of Algarve, \\ 8005-139 Faro, Portugal; jcsantos@ualg.pt \\ 3 Interdisciplinary Centre of Social Sciences (CICS.NOVA.UMinho), School of Psychology, University of Minho, \\ 4710-057 Braga, Portugal; isilva@psi.uminho.pt (I.S.S.); alveloso@psi.uminho.pt (A.V.) \\ 4 Center for Psychology at University of Porto (CPUP), Faculty of Psychology and Educational Sciences, \\ University of Porto, 4099-002 Porto, Portugal; catarina@fpce.up.pt \\ 5 Faculty of Psychology and Educational Sciences, University of Porto, 4099-002 Porto, Portugal; \\ ritamoura@fpce.up.pt \\ * Correspondence: spgoncalves@iscsp.ulisboa.pt
}

Citation: Gonçalves, Sónia P., Joana Vieira dos Santos, Isabel S. Silva, Ana Veloso, Catarina Brandão, and Rita Moura. 2021. COVID-19 and People Management: The View of Human Resource Managers. Administrative Sciences 11: 69. https://doi.org/ 10.3390/admsci11030069

Received: 13 May 2021

Accepted: 7 July 2021

Published: 9 July 2021

Publisher's Note: MDPI stays neutral with regard to jurisdictional claims in published maps and institutional affiliations.

Copyright: (c) 2021 by the authors. Licensee MDPI, Basel, Switzerland. This article is an open access article distributed under the terms and conditions of the Creative Commons Attribution (CC BY) license (https:/ / creativecommons.org/licenses/by/ $4.0 /)$.

\begin{abstract}
COVID-19 has brought an unexpected need for change within organizations, particularly regarding human resource management. The nature of this global crisis has meant that these processes remain under-systematized. The aim of this study, which uses an exploratory design and mixed-methods analysis, is to contribute to describing the changes in human resource management practices and processes that resulted from this pandemic and to present the outlook of human resource managers for the future. One hundred and thirty-six Portuguese companies participated in the study, with the answers provided by their human resource managers. Results show that the main changes have occurred in the processes of work and safety, training, work organization, recruitment and selection, induction and onboarding, and communication. The profiles that emerged showed an association between the level of change and size of the organization. There was an increase in the use of teleworking and layoffs, and a positive assessment of the organizations' level of preparation and adaptation to this crisis. Human resource managers reported that the most evident changes in the future will be associated with the use of technology, teleworking, and work organization. These findings are of the upmost importance, as human resource managers are essential pillars in the adjustment of the organizations to this pandemic situation.
\end{abstract}

Keywords: COVID-19; human resource management; organizations; challenges; changes; preparation; adaptation; teleworking; layoff

\section{Introduction}

The first report on the new coronavirus (SARS-CoV-2) by the World Health Organization (WHO) dates from 21 January 2020 and refers to information which came from the WHO office in China regarding cases of atypical pneumonia of unknown cause, detected in the city of Wuhan. In Portugal, the first cases of SARS-CoV-2 were officially declared by the Directorate-General of Health (Direção-Geral de Saúde-DGS) on 2 March 2020.

At the time, the deep lack of knowledge about this virus, combined with the lack of a vaccine or a cure for COVID-19 according to official information presented by the DGS, made strict containment measures necessary, these varying from country to country. In Portugal, this implied people quarantining themselves from others, applying measures of social distancing, hygiene, and respiratory etiquette, and adopting extreme political measures, such as the state of emergency decreed between 18 March and 2 May 2020. This forced schools, commerce, and non-essential businesses in public and private sectors to 
close. As this was, and to some extent still is, a new disease, albeit linked to existing viruses in circulation in the human environment, the virus's reach and rapid spread have made it an atypical phenomenon, shrouded in uncertainty, and social groups have had to find global means of coping. The economic, social, and family situation of the Portuguese population has since undergone extensive changes, from limiting social interaction with other individuals to finding new forms of work (e.g., fortnightly regimes; teleworking, layoff, etc.).

The challenge presented to the workforce on a global level by COVID-19 has been unprecedented due to its impact on a key aspect of our existence-the survival of people and organizations. Human resource management (HRM) is recognized as having been assigned the role of implementing the plans defined by the political powers in order to maintain social distancing (Koirala and Acharya 2020), thus helping to reduce the spread of the virus. At the same time, the studies carried out in this area (e.g., Elsafty and Ragheb 2020; Koirala and Acharya 2020) have drawn attention to the important role of these professionals in defining strategies that allow people to work from home. This is particularly the case in the use of information technologies, but also in the management of employees' emotional concerns, which are associated with the potential or real impact of the crisis on their work and family dynamics.

In previous years, human resource managers have dealt with different political, economic, and social crises, allowing them to compile a repository of important knowledge in order to better manage its impacts (Psychogios et al. 2016; Bailey and Breslin 2020). During the 2008 financial crisis, for example, we observed very differing responses in Europe, including the introduction of greater flexibility, changes in the structure and design of jobs and, conversely, the option of downsizing. Common HRM practices designed to help companies adapt to crisis situations, such as the economic recession, include: adjustment of wages and workforce (e.g., severances, early retirement and recourse to part-time and temporary workers); reorganization of work schedules (e.g., reducing overtime and flexible working hours); stabilizing the workforce (e.g., encouraging sabbatical leave and taking recourse to layoffs); and at the level of involvement, making more intensive use of communications or altering collective labour agreements (Roche et al. 2011). Out of this wealth of knowledge, not only is the role of leaders also worthy of note in managing crisis situations, but in particular that of human resource managers, whose importance has been reinforced by the pandemic (Caligiuri et al. 2020). In this regard, see, for example, the systematic literature review by Zhong et al. (2021) in which several HRM practices were identified that can assist in the management of the crisis triggered by the current pandemic, or the reflection by Butterick and Charlwood (2021) on the role of HRM in managing the inequalities experienced by different groups of workers in such a situation.

In situations of health crisis, human resource managers play an essential role in responding to the needs of workers as regards to health and safety but also handling issues of anxiety and stress that are known to be exacerbated by the need for virtual work, long working hours, and the working conditions of the "virtual offices", which are not always adequate (Caligiuri et al. 2020; Roche et al. 2011). The study by Nutsubidze and Schmidt (2021), which explored the main challenges of the current pandemic from the perspective of HRM professionals, reinforced this importance, identifying areas such as "managing employee morale, motivation and engagement", "ensuring employee mental health and well-being" or "establishing transparent communication". Furthermore, much of the work is underpaid (Wenham et al. 2020). As such, the crisis which COVID-19 has generated constitutes an unparalleled challenge for the workforce on a global level. A better understanding of the impact of the pandemic at work and on companies has thus become imperative in order to provide better guidance for individuals through this ever-changing situation.

Using an exploratory design with mixed-methods analysis, the goals of this study are to explore (1) changes in Portuguese organizations, considering HRM practices arising from the pandemic situation, as well in work organization processes and the level of preparation 
and adaptation of organizations; and (2) the expectations of human resource managers regarding the future.

\section{Materials and Methods}

\subsection{Sample and Procedure}

One hundred and thirty-six organizations participated in this study, with answers being provided by their human resource managers. Over $80 \%$ of the organizations were situated in the tertiary sector $(n=112 ; 82.4 \%)$ and were mostly medium $(n=58 ; 43.9 \%)$ or large $(n=43 ; 32.6 \%)$ in terms of size (i.e., number of workers). Approximately half were private Portuguese organizations $(n=67 ; 49.3 \%)$, operating in various regions of the country $(n=57 ; 41.9 \%)$. In most organizations $(n=125 ; 91.9 \%)$, there was an area responsible for this aspect of HRM, with approximately $70 \%(n=95 ; 69.9 \%)$ of the cases being hierarchically dependent on the leadership and leaders of the organization. The organizations were located in several locations in Portugal, covering the north, south, and central areas.

This study was approved by the Ethics Committee of the Faculty of Psychology and Education Sciences from University of Porto (2020/07-10b). Given that this research was time sensitive as Portugal was taking the first steps to initiate the deconfinement plan, we used the contact network of the Portuguese Association of People Management in order to rapidly reach a larger number of Portuguese organizations. This allowed us to collect data in a short period of time that more accurately reflected the adaptation period of these companies to the first lockdown in the country due to COVID-19. We also chose to include organizations of different sizes to allow the comparison between organizations with more or less resources (e.g., well-established human resource department). Thus, our sample was recruited using non-probabilistic sampling techniques, namely the convenience and snowballing techniques.

The online collection of data was carried out between May and June 2020 (during and immediately after the end of the first decreed state of emergency in Portugal), using the SurveyMonkey platform. We expected that the online distribution of the survey would facilitate the participation in the study. Moreover, the choice to use this method was congruent with the social distancing measures implemented at the time.

Respondents were informed of the anonymous and confidential nature of the data collected, and it was noted that their participation was voluntary and that there were no monetary or other rewards for participation. Completing the questionnaire took an average of $15 \mathrm{~min}$. All incomplete or incorrectly completed questionnaires were discarded.

\subsection{Instruments}

The data collection questionnaire comprised three main sections. In Section 1, information was collected on the profile of the organization, with questions related to the activity sector, number of professionals, and the organization's geographic distribution, among others. Section 2 aimed to provide a sociodemographic profile of the professional in charge of the HRM department (e.g., age and gender) and also their socio-professional profile (e.g., level of training and years of experience). Section 3 was related to human resources practices in the context of COVID-19. For this purpose, both closed and open-ended answer questions were used.

In particular, a measure was used to profile the level of change in HRM processes (e.g., recruitment and selection, induction and onboarding, labour relations), consisting of 21 items rated on a scale from 1 (no changes) to 3 (has undergone significant changes). For each of the processes indicated, respondents were requested to specify the introduced changes in an open answer. A measure for profiling work situations was also used, according to the Portuguese Labour Code, including: weekend work, rotating shift work; overtime, annual hours in the contract, part-time work, flexible hours, temporary work, fixed-term contracts, working from home, and teleworking. Respondents were requested to indicate the percentage of workers in the organization under these conditions 
on 31 January 2020 and during the first state of emergency, using the following percentage scale: $1=$ not used; $2=0$ to $5 \% ; 3=6$ to $10 \% ; 4=11$ to $20 \% ; 5=21$ to $50 \% ; 6>50 \%$. The next measure was related to the level of adaptation of the organization due to COVID-19 and consisted of a dichotomous answer item (i.e., yes/no) on the need to reduce staff. To further elaborate information on this, there were also two items referring to how well prepared and adapted the organization was for/to the pandemic, on a scale of 1 (not at all prepared/adapted) to 7 (fully prepared/totally adapted). Lastly, an open-ended question asked participants to share their opinion on what changes will come about in the future for HRM as a result of this pandemic.

\subsection{Data Analysis}

The data collected from the closed questions were analysed using the IBM program SPSS (version 26.0), and the analysis procedures included the use of descriptive statistics and multiple correspondence analysis. The data were collected using the open question "In your opinion, what is going to change in HRM because of the pandemic?" and later analysed using the template analysis (King 1998). This analysis method uses a hierarchical coding structure based on the important themes of this study, identified a priori by the researchers, and which later evolved into more specific themes as the analysis progressed and new information was found. An initial template was built upon these themes and used to organize the data in a clear and purposeful way (King 1998). Two members of the research team coded the data independently and later reached a consensus on the template and the hierarchy of themes guaranteeing the consistency of the analysis (Braun and Clarke 2006). The main themes of the initial template were: the role of HRM; HRM practices, the use of teleworking associated with (re)organization of work; and the importance of technology. At the end, a final template was reached integrating some new themes that evolved from the analysis. All respondents answered the open question although some data were not coded, as for example "no comments (p. 125)" or "paradigms (p. 90)".

\section{Results}

Below are the results on the changes identified in HRM practices and processes and their composition according to size of the companies, changes in work situations, and lastly, human resource managers' future outlooks.

\subsection{Changes in Processes of People Management}

Figure 1 details the changes in HRM practices and processes in percentages.

Most HRM processes appear not to have changed. Of these, the processes of outplacement $(n=118 ; 88.7 \%)$, expatriation $(n=114 ; 85.7 \%)$, and career management $(n=104$; $78.2 \%$ ) can be highlighted. Among the significant processes that have undergone minor adjustments are internal communications processes $(n=75 ; 56.4 \%)$. The process in which the most significant changes have occurred is that of work and safety $(n=57 ; 42.9 \%)$.

Respondents were also asked to specify the changes introduced for each process in an open-ended answer. The following changes were among the most frequent answers: (1) it was suspended; (2) it went online; and (3) it continues to be face-to-face, but with safety measures. It should also be noted that there has been an increase in processes for managing exits. Additionally, respondents highlighted that internal communications had intensified. There were also many complementary answers obtained for health and safety at work, with a focus on implementing contingency plans and measures to ensure workers' physical safety, increasing specific training for work and safety, and introducing measures to foster workers' health. 


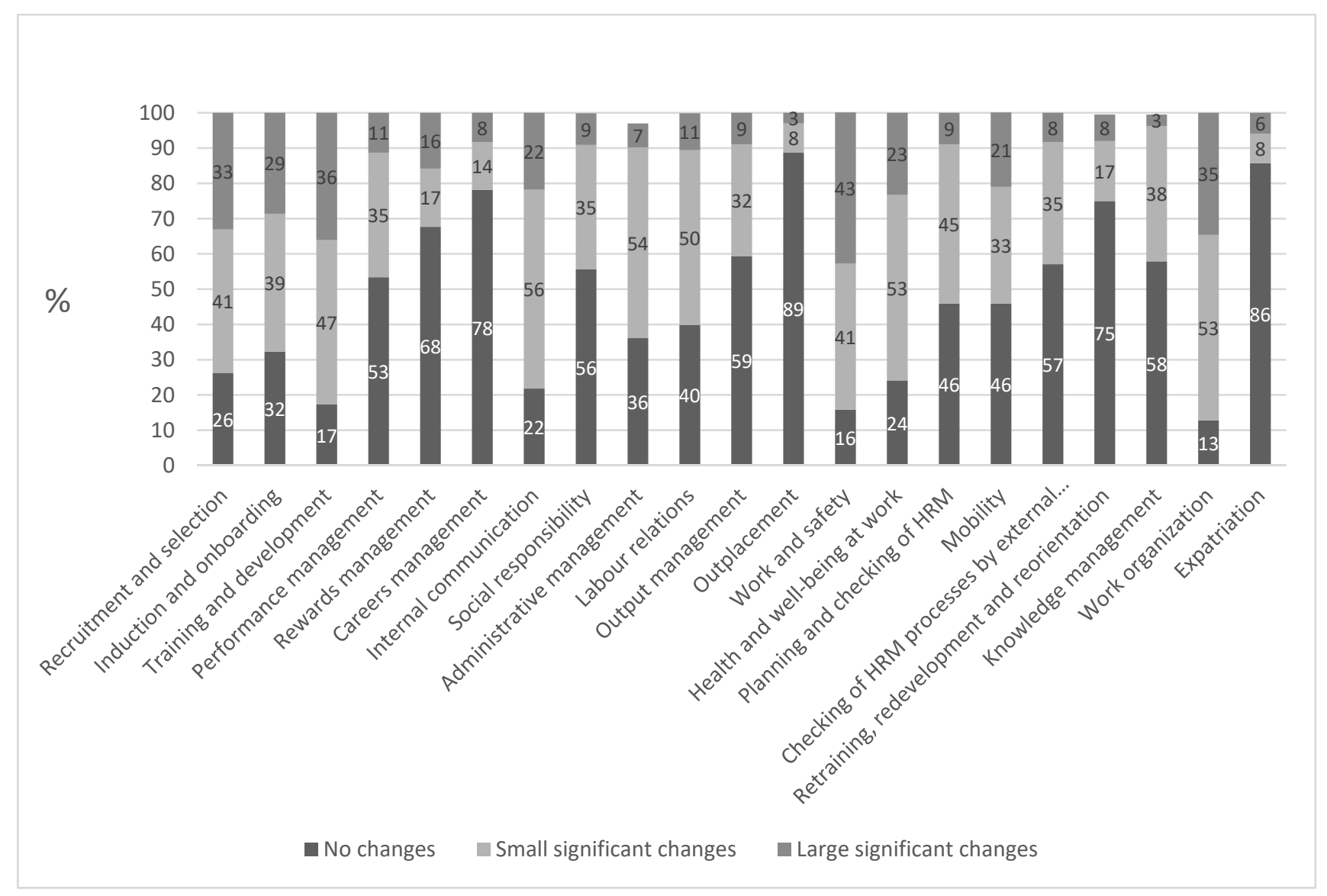

Figure 1. Changes in HRM practices and processes.

\subsection{Composition of Changes in People Management Processes}

A multiple correspondence analysis was carried out in order to map the changes in the processes of people management which have resulted from the pandemic, factoring in the size of the companies. Multiple correspondence analysis (MCA) is a data analysis technique that uses multiple categorical variables and seeks to identify associations between the levels of those variables (LeRoux and Rouanet 2010). This technique represents the data as points in a 2- or 3-dimensional space. In this study, results are presented in a 2-dimensional space based on the level of change and the size of company. The results can be observed in Figure 2.

The process indicators that revealed greater heterogeneity in terms of changes were included in the multiple correspondence analysis in order to obtain an interpretable solution in terms of the number of indicators. These were: (1) induction and onboarding; (2) wellbeing and health at work; (3) internal communications; (4) training and development; (5) mobility; (6) recruitment and selection; and (7) job security. The size of the organization was considered in terms of the number of workers.

The results show that the variables are structured on two axes, one related to changes in processes of people management and the other to the size of the organization, leading to the structure shown in Figure 2. The 2-dimensional space shows well defined compositions which reflect the existence of three groups of interdependence between the level of variables: (1) small companies in which the processes of HRM have not changed; (2) micro companies in which the processes have undergone minor adjustments; and (3) large companies in which the processes have undergone significant changes. Medium-sized companies did not fit into any of the emerging homogeneous groups, which may indicate greater diversity of levels of change. 

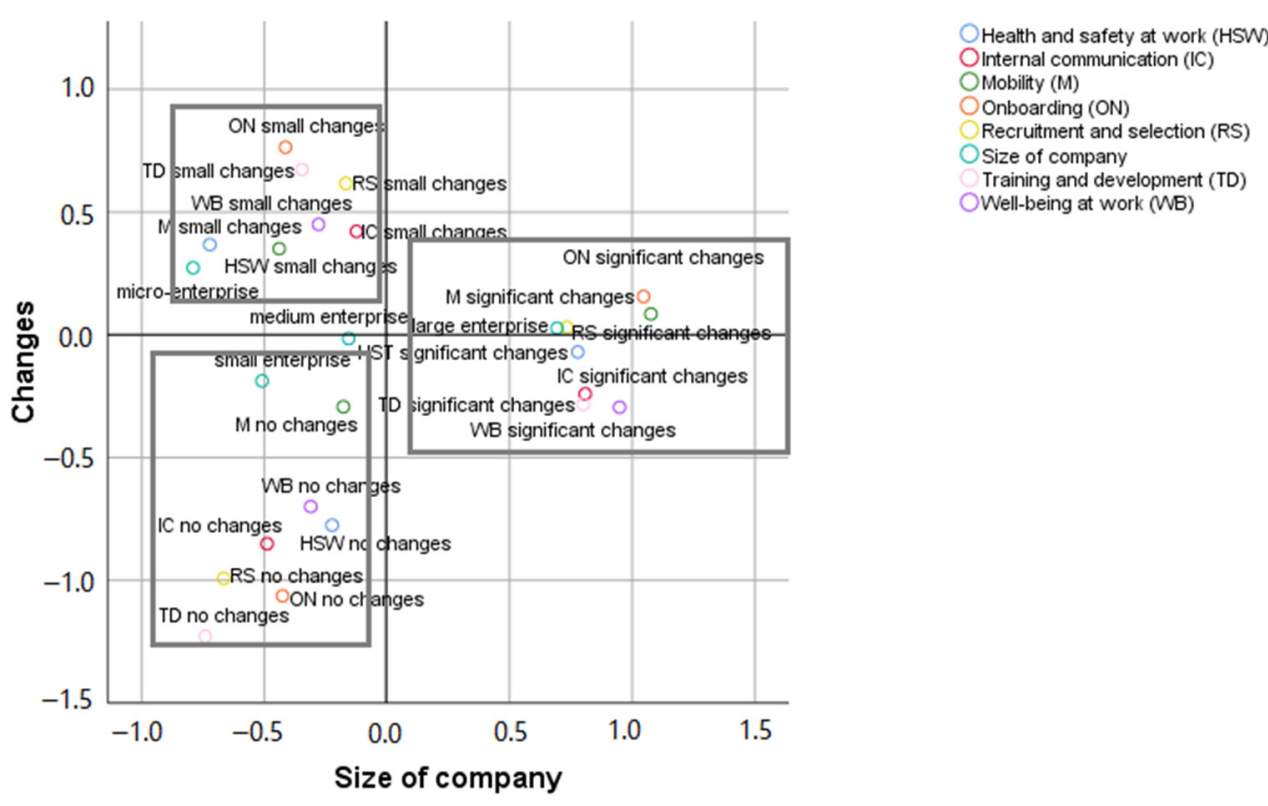

Figure 2. Changes in HRM practices and processes by company size.

\subsection{Changes in Working Situations}

In order to analyse working situations, human resources managers were asked to indicate the percentage of workers in their organization in each of the following situations, first on 31 January 2020 and then during the first decreed state of emergency (from March to May 2020): weekend work; rotating shift work; overtime; annual hours in the contract; part-time work; flexible schedules; temporary job; fixed-term contracts; working from home; and teleworking.

The work situations which were subject to more explicit changes for more than $50 \%$ of workers were teleworking and the emergence of layoffs (see Table 1 for more details). For example, teleworking on 31 January 2020 was not widely used ( $n=90 ; 66.2 \%)$ while during the state of emergency, more than $50 \%$ of the workers in the organizations under study were working in that situation $(n=53 ; 39.0 \%)$. All other situations were either not used or were residual in number and have not been listed for that reason.

Table 1. Work situations with the greatest changes—-teleworking and layoffs.

\begin{tabular}{|c|c|c|c|c|c|c|}
\hline & \multicolumn{4}{|c|}{ Teleworking } & \multirow{2}{*}{\multicolumn{2}{|c|}{ Layoffs }} \\
\hline & \multicolumn{2}{|c|}{ On 31 January 2020} & \multicolumn{2}{|c|}{$\begin{array}{l}\text { During the First State of } \\
\text { Emergency (March to } \\
\text { May 2020) }\end{array}$} & & \\
\hline & Frequency & Percentage & Frequency & Percentage & Frequency & Percentage \\
\hline Not used & 90 & 66.2 & 18 & 13.2 & 78 & 57.4 \\
\hline $1-5 \%$ & 22 & 16.2 & 15 & 11.0 & 8 & 5.9 \\
\hline $6-10 \%$ & 9 & 6.6 & 19 & 14.0 & 8 & 5.9 \\
\hline $11-20 \%$ & 5 & 3.7 & 10 & 7.4 & 5 & 3.7 \\
\hline $21-50 \%$ & 4 & 2.9 & 21 & 15.4 & 5 & 3.7 \\
\hline More than $50 \%$ & 5 & 3.7 & 53 & 39.0 & 31 & 22.7 \\
\hline $\begin{array}{l}\text { Did not } \\
\text { answer }\end{array}$ & 1 & 0.7 & 0 & 0.0 & 1 & 0.7 \\
\hline Total & 136 & 100.0 & 136 & 100.0 & 136 & 100.0 \\
\hline
\end{tabular}

Data regarding the question of whether staff needed to be downsized in view of the pandemic revealed that most respondents reported no need to downsize $(n=93 ; 69.9 \%)$. In cases with affirmative answers, there was a question about the measures taken during 
downsizing, with the following being mentioned: non-renewal of contracts $(n=34 ; 25.6 \%)$ and severances $(n=1 ; 0.8 \%)$.

\subsection{Preparation and Adaptation to COVID-19}

For the question about the organizations' level of preparation in the face of a situation such as the COVID-19 pandemic, the most frequent answer was 4, on a scale of 1 (not prepared at all) to 7 (fully prepared). The most frequent score for the question about the level of adaptation of the organization to the situation was 6. Thus, the results suggest that human resource managers considered that the organizations they work for were somewhat prepared for the outbreak and were able to adapt very well, as shown in Table 2.

Table 2. Organizations' level of preparation and adaptation for dealing with the COVID-19 outbreak.

\begin{tabular}{ccccc}
\hline & \multicolumn{2}{c}{ Level of Preparation } & \multicolumn{2}{c}{ Level of Adaptation } \\
\hline & Frequency & Percentage & Frequency & Percentage \\
\hline 1 (Not at all pre- & 16 & 11.8 & 0 & 0 \\
pared/adapted) & 21 & 15.4 & 6 & 4.4 \\
2 & 18 & 13.2 & 6 & 4.4 \\
3 & 27 & 19.9 & 14 & 10.3 \\
4 & 26 & 19.1 & 28 & 37.5 \\
5 & 21 & 15.5 & 51 & 22.8 \\
6 & 7 & 5.1 & 31 & 100.0 \\
7 (Fully pre- & 136 & 100.0 & 136 &
\end{tabular}

\subsection{Outlook for the Future}

The template analysis of the data collected with the open question "In your opinion, what is going to change in HRM because of the pandemic?" allowed an assessment of HR managers' expectations concerning the main changes in HRM in the post-pandemic future.

The nine main themes and related specialized subthemes that emerged from the analysis can be observed in Table 3, in the final template: HRM role and practices, organizational processes (such as leadership, communication, etc.), teleworking, technology, work organization, work-life balance, and workplace reorganization. Additionally, the respondents also anticipated important changes that are transversal to the organization and their workforce, namely: less travel, new checking mechanisms and more work, and the demand for a more flexible and multi-skilled workforce. According to the HR managers, the more expressive domain for changes in the future are related with technology: not only teleworking and homework but all the process related that support the use of technology to perform work such as work organization; communication and leadership of remote workers. Although most of the respondents presented positive projections of future changes that suggest the empowerment of HRM, some $(n=7 ; 5 \%)$ advocates that nothing was going to change. These results will be presented and explained in greater detail in the next sections, illustrated with some examples from the data. Respondents are represented by numbers, referring to their position in the database (for example, p. 1).

\subsubsection{HRM Role}

The role played by HMR is changing due to the pandemic, according to the respondents $(n=18 ; 13 \%)$, because organizations are changing to " $\ldots$ peopleless organisations where they are leaving their setting or are on a hybrid regime" (p. 9). HRM is going to be "... more important in the organization" (p. 38) and "more dependent of the Board" (p. 31) anticipating " ... new trends: digital or remote work are no longer be future but to be transversal reality" (p. 28). 
Table 3. Coding template for human resource managers' outlooks.

\begin{tabular}{|c|c|c|}
\hline $\begin{array}{l}\text { Initial Template } \\
\text { Main Themes }\end{array}$ & $\begin{array}{l}\text { Final Template } \\
\text { Main Themes }\end{array}$ & Subthemes \\
\hline 1. HRM role & \multirow{3}{*}{ 1. HRM role } & 1.1. Role \\
\hline \multirow{4}{*}{$\begin{array}{l}\text { (Function of HRM in the } \\
\text { organization) }\end{array}$} & & 1.2. Administrative \\
\hline & & 1.3. Planning \\
\hline & \multirow{7}{*}{ 2. HRM practices } & 2.1. Induction \\
\hline & & 2.2. Recruitment and selection \\
\hline \multirow{5}{*}{$\begin{array}{l}\text { 2. HRM practices } \\
\text { (Group of activities developed } \\
\text { in a management system } \\
\text { of people) }\end{array}$} & & 2.3. Training \\
\hline & & $\begin{array}{l}\text { 2.4. Performance management } \\
\text { and evaluation }\end{array}$ \\
\hline & & $\begin{array}{l}\text { 2.5. Health, safety, and } \\
\text { hygiene }\end{array}$ \\
\hline & & 2.6. Remuneration \\
\hline & & 2.7. Careers \\
\hline \multirow{4}{*}{$\begin{array}{l}\text { 3. Organizational processes } \\
\text { (HRM actions that support the } \\
\text { organization_soft dimension) }\end{array}$} & \multirow{4}{*}{ 3. Organizational processes } & 3.1. Leadership \\
\hline & & 3.2. Communications \\
\hline & & 3.3. Work Team \\
\hline & & 4.1. Flexibility \\
\hline 4. Teleworking & 4. Teleworking & $\begin{array}{l}\text { 4.2. Suitability of teleworking } \\
\text { for different roles }\end{array}$ \\
\hline \multirow{8}{*}{$\begin{array}{l}\text { 5. Technology } \\
\text { (Use of information } \\
\text { technology; digitalization, } \\
\text { automation, etc.) }\end{array}$} & 5. Technology & \\
\hline & \multirow[t]{3}{*}{$\begin{array}{l}\text { 6. Work organization } \\
\text { (Management by objectives; } \\
\text { time management; methods; } \\
\text { work schedules, etc.) } \\
\text { 7. Work-life balance }\end{array}$} & \\
\hline & & 8.1. Reduced workforce \\
\hline & & 8.2. Less travel \\
\hline & \multirow{3}{*}{$\begin{array}{l}\text { 8. Impact } \\
\text { (Impact of pandemic on HRM, } \\
\text { workers and work) }\end{array}$} & $\begin{array}{l}\text { 8.3. New checking } \\
\text { mechanisms }\end{array}$ \\
\hline & & $\begin{array}{l}\text { 8.4. More work, flexibility and } \\
\text { multiskilled workforce }\end{array}$ \\
\hline & & 8.5. Workers' insecurity \\
\hline & 9. Premises/workspaces & 9.1 Planning office size \\
\hline
\end{tabular}

This will require a greater focus on planning (" ... the workforce must adapt to this new situation", p. 83); "Improvement in administrative processes" (p. 7) and "Contractual flexibility" (p. 86). It also will demand "greater control of processes" (p. 78) and "higher performance and productivity of HRM" (p. 22) which " .. will be oriented by objectives (p. 37).

\subsubsection{HRM Practices}

There are changes foreseen in several HRM practices $(n=52 ; 38 \%)$ mostly because of the intensive use of technologies, among which can be highlighted: the way of carrying out induction ("... Adaptation of onboarding ...", p. 35) $(n=2 ; 1.5 \%)$; recruitment and selection ( $n=10 ; 7.35 \%)$ by "Rethinking [ . . ] current methods", (p. 12); and using "online recruitment" (p. 108); and training that will become " $100 \%$ online training" (p. 39). Training is the HRM practice that is more referred by the participants $(=15 ; 11 \%)$ as one of the practices that will support change and "ensure that employees acquire new skills for this new reality" (p. 86).

In addition, performance management $(n=6 ; 4.4 \%)$ and evaluation will change towards emphasizing performance (" ... performance having greater relevance than working time", p. 81). Respondents are divided concerning the theme of remuneration $(n=2 ; 1.5 \%)$. While some expect " . . increasing rewards for workers" (p. 32); others expect "freezing [ ... ] of rewards" (p. 40) with careers $(n=1 ; 0.74 \%)$ are also facing “ . . freezing ... ", p. 40). 
However, health, safety, and hygiene are receiving more attention ( $n=11 ; 8 \%)$, specifically: "... emergency and safety plans" (p. 34), and "more safety and hygiene measures" (p. 39). Work team is receiving from HR managers $(n=5 ; 3.7 \%)$ some attention in the sense of becoming " ... more cohesive, to the extent that each person feels that they are part of the success" (p. 27) and as they are concerned how, in the future, they are going to be able to "... promote a relation of trust in the work team" (p. 9) in a more technological and remote work environment. They expect this will demand "new team monitoring methodologies ... " (p. 56).

\subsubsection{Organizational Processes}

Twenty-eight respondents $(n=28 ; 21 \%)$ point out specific organizational processes in which they expect some changes to be introduced, in cooperation with leaders, namely in: work engagement (" . . need to implement measures to increase organisational commitment and engagement ...", p. 104); “Organisational change [ . . ] motivational monitoring", p. 46); and in human relationships ("Maintaining a good relationship despite distancing ... ", p. 91). Particular attention was paid to communication processes that must be "... adapted to these new times with special emphasis on psychosocial and hygienic-sanitary matters" (p. 17), "Reinforced internal communications ..." (p. 65); and leadership, by introducing "... new forms of leadership" (p. 122).

\subsubsection{Teleworking, Technology, and Work Organization}

The most far-reaching future changes are associated with the use of technology $(n=18$; $13 \%)$ and teleworking $(n=52 ; 38 \%)$, as well as work organization $(n=30 ; 22 \%)$. Organizational use of technology in the future from an HRM perspective means "greater use and adoption of new information and communications technologies, particularly tools for collaboration and teleworking [ . . ]" (p. 17), and "going online or for internal and external meetings [ ... ] on platforms that encourage information sharing and make teamwork and the company as a whole more agile ..." (p. 99). Some suggestions from respondents were: "Work organisation [ ... ] the way of working and time management" (p. 22), "redefining work methodologies (e.g., video rather than face-to-face meetings" (p. 26), "organisation of working hours, [ . . ] objective-based work" (p. 34), and "Flexible means of work provision" (p. 74).

One important change pointed out by respondents was "The company's vision regarding teleworking" (p. 122), as there will be "Greater openness to facilitating teleworking for some employees" (p. 16), " ... in the public sector as well" (p. 18) and, consequently, "Implementing flexible schedules and interim teleworking regimes to enable this to be accommodated" (p. 24). Also, according to one respondent ( $n=1 ; 0.74 \%$ ) there will be a future redesign of the workplaces, specifically "Planning the size of offices" (p. 36).

Moreover, the work-life balance was also mentioned $(n=4 ; 2.9 \%)$ : "Reconciling family and professional life must be a clear priority" (p. 37), and an "Emotional framework for knowing how to separate work and home when they happen in the same space" (p. 96).

\subsubsection{Impact of Changes and Workspaces}

According to participants $(n=22 ; 16.7 \%)$, the changes will have various impacts on the organization and workforce, namely: (1) a decrease in the workforce, either due to "severances" (p. 100) or a reduction in hiring (" ... reduction [ . . ] RES", p. 3), and "a decrease in turnover" (p. 3); (2) being away from the workplace, as in "Less use of mobility and travel" (p. 39), and "employees being more absent" (p. 47). As the presence of workers in the workplace will be different, this will, as anticipated by the respondents, demand (3) new checking mechanisms, particularly " ... a different view of the means of managing and checking the mechanisms associated with each employee" (p. 126); (4) more work flexibility in the sense of "expanded workload, flexibility and versatility", (p. 49). Lastly, workers will experience (5) greater job insecurity given that" ... People will feel more insecure" (p. 116).

It should also be noted that some participants associated the reduced presence of workers in organizations with a " ... very positive impact on productivity" (p. 58), "the 
impersonality in some services is predicted because there is no direct personal contact." (p. 103) and "changes in industrial relations" (p. 130).

\section{Discussion}

The first objective of this study was to pinpoint and systematize the changes in HR which have emerged in Portuguese organizations as a result of the COVID-19 pandemic, viewed from the perspective of human resource managers. Overall, the results indicate that those HRM processes which have undergone most changes are related to internal communications (especially, small adjustments) and work and safety (the area that has seen the broadest changes). Considering that the pandemic immediately brought issues to light that could compromise people's health and safety, it was to be expected that work and safety would be the area that required organizations to make the greatest adjustments. On the other hand, when these adjustments in safety procedures represent changes in the organizational life, it requires great effort to communicate and explain them to workers. In fact, one of the aspects referred to as critical in organizational change processes refers to the internal process of communication/dissemination (e.g., Neill et al. 2020). In the specific case of health and safety at work, additional answers support this interpretation, with the implementation of contingency plans being one of the aspects mentioned, for example. Additional answers also refer to the importance of communication in combination with other processes, where work (re)organization stands out, in particular the use of teleworking (one of the two most significant changes in work situations), with aspects such as reinforcement of asynchronous communication or use of new tools. The use of technology also emerges in processes such as recruitment and selection or training and development. HR issues such as "employee wellbeing", "remote work", and "communication" were also identified by Zhong et al. (2021) as those which have been greatly impacted by the current pandemic.

A more detailed analysis of the relation between HRM practices and processes and the size of the organization evinces differences: the largest companies were characterized as having made the most changes, in contrast to small ones, which made none. The literature that addresses analysis of HRM practices between large and small companies (e.g., Deshpande and Golhar 2020) shows that the former tends to have more formalized and coordinated practices because they have greater resources, including specialized knowledge of function (Keating et al. 1999). In our study, most human resource managers have higher levels of education in domains connected with the area, so they can be expected to have specialized knowledge of HRM practices and processes per se and are therefore more able to bring about adaptations to crises, such as the current pandemic. In the study by Adikaram et al. (2021), factors such as the level of preparedness, nature of the industry, availability of resources, and role of the human resources professionals were identified as critical in the process of adaptation of organizations to the pandemic. Additionally, concerning the characteristics of the organization, Waldkirch's (2021) analysis points out that the impact of the pandemic was greater in large companies, manufacturing companies, and companies that rely more heavily on imported inputs.

The serious economic crisis which Portugal went through about a decade ago may also help explain why these human resource managers feel that the organizations where they work were somewhat prepared for the outbreak and that they have, at the time of data collection, adapted well to these situations. This crisis not only demanded major restructuring in many organizations, but it might also have worked as a process of "natural selection", leaving organizations better equipped. Moreover, the use of teleworking and layoffs was notable in companies in Portugal as a response to the pandemic, most probably as a result of exceptional and temporary measures implemented in the country with state support.

It should be noted that the outlook of human resource professionals on upcoming changes refers to various dimensions-roles, practices, and processes-expressing the wide impact of COVID-19. In particular, teleworking was one of the upcoming changes which was most stressed by human resource managers. This finding seems to be associated with 
two important aspects that will support future interventions in HRM: (1) the change in work organization and the design of work which will support remote work, while also considering mixed solutions, that is, greater flexibility in the means and place of work; and (2) using technology for communication (a result equally evidenced in the quantitative data), which will be central to maintaining worker cohesion and their relationship with the organization. Technology has emerged as a facilitator for: (1) communicating; (2) digitalizing; (3) reducing the impact of travel; (4) improving administrative processes; and (5) supporting HRM practices. The outlook on technology which the pandemic has "forced" people to use more intensively is therefore positive and shows positive results.

A central concern as regards to the future is related to organizational processes which focus on maintaining organizational cohesion and the role of HRM. Their role, in response to the pandemic, will be to care for people and their relationship with the organization and ensure their engagement, so that people can work together as a team and communicate.

Where there will be fewer changes, according to respondents, is in HRM practices. The online approach is foreseeable. For example, there will be changes in: (1) the profiles required in recruitment and selection, given that people will work remotely; (2) performance management and evaluation, which will focus more on objectives and less on work time; (3) and training, which will have an online/e-learning component focusing on providing workers with digital skills. Accordingly, various challenges are anticipated. As HRM is expected to outline strategies to cope with the envisaged crises (Koirala and Acharya 2020), this study can be considered as providing input for the management of such processes.

Regarding the future impacts of experiences which have emerged from the pandemic, respondents refer to: (1) reduction in the workforce (e.g., severances, less hiring, and less turnover, as people want to stay in the company); (2) reconciling work/family/leisure time; (3) a concern over management of spaces (i.e., working and living in the same space is demanding); (4) and workers' feelings of insecurity. These feelings will most certainly require preventive action by HRM, which will endeavour to reduce workers' perceptions of insecurity. An impact on productivity is also expected, as workers will travel less, be less tired, and work more. New leadership styles that will emerge must also be acknowledged, as leaders will have to manage teams that do not interact face-to-face, which brings us directly to the concept of e-leadership and what it implies for these new work formats (Machado and Brandão 2019).

\section{Conclusions}

In terms of the changes made to each HRM process, apart from layoffs and the continuation of face-to-face activities, albeit with modified safety measures or going online, the results merit reflection and monitoring. By way of illustration, induction and onboarding is an essential process for workers to adapt (Bauer et al. 2007) and so the following question should be asked: what will the repercussions of the changes that are being implemented be in terms of the worker's life in the organization? As another example, internal communication seems to have undergone a process of intensification and innovation. Given that the literature points to positive relationships between internal communication and professionals' behaviours and attitudes (Men and Yue 2020; Neill et al. 2020), what results can be expected in the long term? Will enhanced communication mean that the pandemic tests leaders in all sectors around the world? These questions should be addressed by human resource managers in a timely manner to ensure the continuity of organizations during and after the pandemic.

Despite the results which have come to light, the study found some limitations that future research should attempt to overcome. First, the focus of this study was to analyse human resource managers' viewpoints. However, to better understand organizations' current situation, it is also important to gather workers' perceptions on these matters. Such research could also be a complement to existing knowledge, using analysis of documents and interviews with organizational stakeholders, and thus guaranteeing a holistic view. In addition, the present study is cross-sectional, so it would be interesting to complement it 
with a study of a longitudinal nature to understand how managers' perspectives evolve in the face of the current epidemiological situation, which is still unpredictable. An attempt could be made, for example, to understand if the future outlooks identified here will materialize. Another aspect has to do with the sample. The online collection procedure meant that the answers were essentially from professionals in medium-sized or large companies. It would also be of interest to learn about the experiences and perceptions of small and medium-sized (SMEs), as well as micro-companies, as these are quite prevalent in Portugal and therefore should be represented.

Nevertheless, these findings are an important step in characterizing the changes that HRM has undergone during this crisis. As the COVID-19 pandemic emerged unexpectedly and is set to continue indefinitely, the continuous study of its repercussions for organizations is essential for good management as well as for associated learning processes. Thus, as concluded in the systematic literature review by Zhong et al. (2021), the COVID-19 pandemic has challenged the maintenance of conventional HRM practices, demanding both conceptual and empirical attention from the scientific community in order to deal with such challenges. In fact, this concern should not only be on behalf of those who research HRM, but, as Butterick and Charlwood (2021) highlight, also on behalf of those who teach and practice it to improve its role, especially in mitigating the unequal work experiences accentuated by the current pandemic.

Author Contributions: Conceptualization, S.P.G., J.V.d.S., I.S.S., A.V. and C.B.; Data curation, S.P.G.; Formal analysis, S.P.G., J.V.d.S., A.V. and C.B.; Funding acquisition, C.B.; Investigation, S.P.G., J.V.d.S., I.S.S., A.V. and C.B.; Methodology, S.P.G., J.V.d.S., I.S.S., A.V. and C.B.; Project administration, C.B.; Resources, S.P.G. and C.B.; Supervision, S.P.G.; Validation, S.G., J.V.d.S., I.S.S., A.V., C.B. and R.M.; Visualization, S.P.G. and R.M.; Writing-original draft, S.P.G., J.V.d.S., I.S.S., A.V. and C.B.; Writingreview \& editing, S.P.G. and R.M. All authors have read and agreed to the published version of the manuscript.

Funding: This research was funded by FCT—Fundação para a Ciência e a Tecnologia, I.P (Gender Research 4 COVID-19, project 126).

Institutional Review Board Statement: The study was conducted according to the guidelines of the Declaration of Helsinki and approved by the Ethics Committee of Faculty of Psychology and Educational Sciences, University of Porto (Porto, Portugal) (2020/07-10b).

Informed Consent Statement: Informed consent was obtained from all subjects involved in the study.

Data Availability Statement: The data that support the findings of this study are available on request from the corresponding author, Sónia P. Gonçalves, spgoncalves@iscsp.ulisboa.pt.

Acknowledgments: The authors would like to thank the Associação Portuguesa de Gestão de Pessoas-APG, a partner of this study, for their assistance during data collection.

Conflicts of Interest: The authors declare no conflict of interest. The funders had no role in the design of the study; in the collection, analyses, or interpretation of data; in the writing of the manuscript; or in the decision to publish the results.

\section{References}

Adikaram, Arosha B., Hewawasam P. S. Priyankara, and Naotunna P. G. S. I. Naotunna. 2021. Navigating the crises of COVID-19: Human Resource professionals battle against the pandemic. South Asian Journal of Human Resources Management. [CrossRef]

Bailey, Katie, and Dermot Breslin. 2020. The COVID-19 pandemic: What can we learn from past research in organizations and management? International Journal of Management Reviews. [CrossRef]

Bauer, Talya N., Todd Bodner, Berrin Erdogan, Donald M. Truxillo, and Jennifer S. Tucker. 2007. Newcomer adjustment during organizational socialization: A meta-analytic review of antecedents, outcomes, and methods. Journal of Applied Psychology 92: 707-21. [CrossRef] [PubMed]

Braun, Virginia, and Victoria Clarke. 2006. Using thematic analysis in psychology. Qualitative Research in Psychology 3: 77-101. [CrossRef]

Butterick, Mark, and Andy Charlwood. 2021. HRM and the COVID-19 pandemic: How can we stop making a bad situation worse? Human Resource Management Journal, 1-10. [CrossRef] 
Caligiuri, Paula, Helen De Cieri, Dana Minbaeva, Alain Verbeke, and Angelika Zimmermann. 2020. International HRM insights for navigating the COVID-19 pandemic: Implications for future research and practice. Journal of International Business Studies 51: 697-713. [CrossRef] [PubMed]

Deshpande, Satish P., and Damodar Y. Golhar. 2020. International HRM insights for navigating the COVID-19 pandemic: Implications for future research and practice. Journal of Small Business Management 32: 49-56.

Elsafty, Ashraf, and Mohammad Ragheb. 2020. The role of Human Resource Management towards employees retention during Covid-19 pandemic in medical supplies sector-Egypt. Business and Management Studies 6: 5059. [CrossRef]

Keating, José, Isabel Soares Silva, and Hélder Lopo Almeida. 1999. Gestão de recursos humanos em pequenas e médias empresas. Psicologia 13: 237-55. [CrossRef]

King, Nigel. 1998. Template analysis. In Qualitative Methods and analysis in Organizational Research: A Practical Guide. Edited by Gillian Symon and Cathy Cassell. Thousand Oaks: Sage Publications Ltd., pp. 118-34.

Koirala, Jyoti, and Suman Acharya. 2020. Dimensions of Human Resource Management evolved with the outbreak of COVID-19. SSRN Electronic Journal. Available online: https:/ / ssrn.com/abstract=3584092 (accessed on 5 January 2021).

LeRoux, Brigitte, and Henry Rouanet. 2010. Multiple Correspondence Analysis. Vol.07-163 of Sage University Paper Series on Quantitative Applications in the Social Sciences. Thousand Oaks: Sage Publications.

Machado, Ana Marisa, and Catarina Brandão. 2019. Leadership and technology: Concepts and questions. In New Knowledge in Information Systems and Technologies. WorldCIST'19 2019. Advances in Intelligent Systems and Computing. Edited by Álvaro Rocha, Hojjat Adeli, Luís Paulo Reis and Sandra Costanzo. Cham: Springer, vol. 931, pp. 764-73. [CrossRef]

Men, Linjuan Rita, and Cen April Yue. 2020. Creating a positive emotional culture: Effect of internal communication and impact on employee supportive behaviors. Public Relations Review 45: 101764. [CrossRef]

Neill, Marlene S., Linjuan Rita Men, and Cen April Yue. 2020. How communication climate and organizational identification impact change. Corporate Communications: An International Journal 25: 281-98. [CrossRef]

Nutsubidze, Nino, and Dusana Alshatti Schmidt. 2021. Rethinking the role of HRM during COVID-19 pandemic era: Case of Kuwait. Review of Socio-Economic Perspectives 6: 1-12. [CrossRef]

Psychogios, Alexandros, Chris Brewster, and Emma Parry. 2016. Western European HRM: Reactions and adjustment to crises. In International Human Resource Management_Contemporary HR issues in Europe, 3rd ed. Edited by Michael Dickmann, Chris Brewster and Paul Sparrow. London: Routledge, vol. 931, pp. 115-34.

Roche, William K., Paul Teague, Anne Coughlan, and Majella Fahy. 2011. Human Resources in the Recession: Managing and Representing People at Work in Ireland-Executive Summary. Carlow: Labour Relations Commission.

Waldkirch, Andreas. 2021. Firms around the World during the COVID-19 Pandemic. Journal of Economic Integration 36: 3-19. [CrossRef]

Wenham, Clare, Julia Smith, and Rosemary Morgan. 2020. COVID-19: The gendered impacts of the outbreak. The Lancet 395: 846-48. [CrossRef]

Zhong, Yifan, Yameng Li, Jian Ding, and Yiyi Liao. 2021. Risk management: Exploring emerging Human Resource issues during the COVID-19 pandemic. Journal of Risk and Financial Management 14: 228. [CrossRef] 